\title{
To Reduce Magnetic Inrush Current by Point Wave Switching Method
}

\author{
Pawar Akash', Kamal Sundeep ${ }^{2}$ \\ ${ }^{1}$ Electrical Department, Pune University, ZEAL Education Society, Pune, Maharashtra, India \\ ${ }^{2}$ Electrical Department, Pune University, ZEAL Education Society, Pune, Maharashtra, India
}

\begin{abstract}
At the time of transformer energization, a high current will be drawn by the transformer. This current is mentioned transient inrush current and it may rise to ten times the nominal full load current of transformer during operation .This current can produce mechanical stress to the transformer, causes protection system malfunction and it often affect the power system quality and may disrupt the operation of sensitive electrical loads such as computers and medical equipment connected to the system. Energization transients current reduce by use of point on wave switching at the time transformer is initially connected to supply. In this paper the simulations and the experimental results on a three-phase transformer for reduction of inrush currents. An electronic devices threephase switching controller has been designed and some thyristors are used for switching power to the transformers. Reduction of magnetic inrush current and the way to control of energization transients currents have become important concerns to the power industry for engineers.
\end{abstract}

Keywords: Transformer current, magnetic inrush current, Optocoupler, Triac

\section{Introduction}

When a transformer is energized, then depending on its switching at and high magnetic flux in the transformer core, it may produce a high transient magnetic inrush currents is produce which up to ten cycle times of its rated no-load current. The magnetizing inrush currents in power transformers can cause electromechanical shock on transformer bushings, core and windings, malfunctioning of protection systems fail and create saturation in the core severe power quality reduce problem created in the power transformer. The magnetic inrush currents in transformer may last in about 10 cycles. Energisation magnetic current reducre the performance of a transformer. The design of a device to control in order to provide voltage delay angle controlled switching device to connect the rated voltage to transformer primary circuit at the starting current can be very effective.

The point on wave control is designed to energize the transformer at the optimal point on wave the voltage waveform, and its intention is to reduce transformer transient inrush at the time of energization of starting current. In a transformer circuit the voltage and the current waveform are $90^{\circ}$ away apart from each other. Transformer current and flux are normally in phase so angle between current and flux is zero voltage and flux are $90^{\circ}$ apart as well as shown in fig: 1 . Without point on wave switching, magnetic inrush current a transformer may result in core saturation, power quality decrease where, a small increase of flux which leads to a large increase in current as shown in fig: 2 .

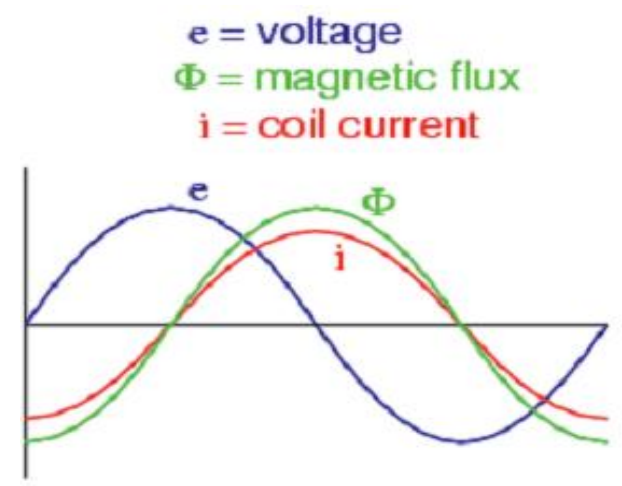

Flux and winding current at their negative peaks.

Figure 1: Voltage, current and flux waveform

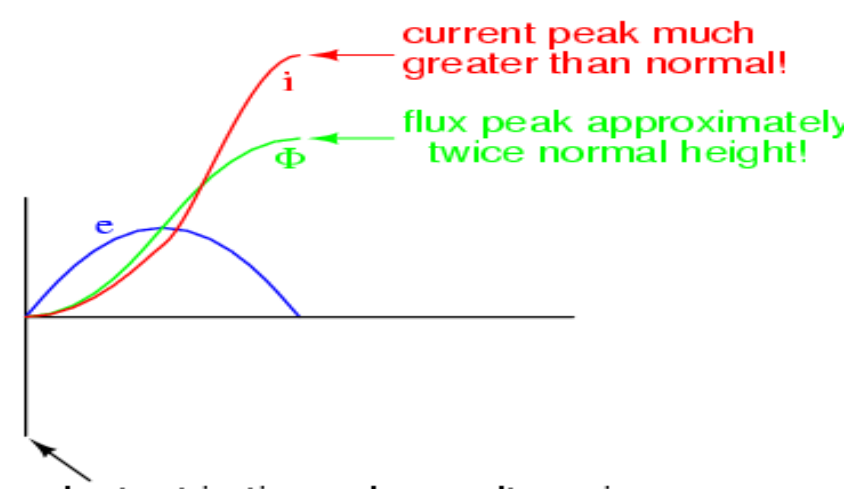

Instant in time when voltage is zero,

Figure 2: Transient magnetic inrush current

\section{Inrush Current}

The transient component $\Phi \mathrm{t}$ will be decay according to the circuit time constant $(\mathrm{L} / \mathrm{R})$ which is constant, the flux transient will through a maximum value of $2 \Phi \mathrm{m}$ So this phenomenon called as doubling effect. The corresponding exciting current is be very high as the core gets deep 


\section{International Journal of Science and Research (IJSR) \\ ISSN (Online): 2319-7064 \\ Index Copernicus Value (2013): 6.14 | Impact Factor (2014): 5.611}

saturation region of magnetization $(\mathrm{Bm}=2 * 1.4=2.8 \mathrm{~T})$; which may indeed be as high the normal exciting current, (normal exciting current being $0.05 \mathrm{pu}$ ) producing electromagnetic forces 25 times the normal rated current. This is why windings of highly transformer strong braced.

$\Phi \mathrm{t}=(\Phi \mathrm{m}+\Phi \mathrm{r}) \boldsymbol{e}^{\wedge}\left(-\frac{\boldsymbol{r} \mathbf{1 t}}{\boldsymbol{L} \mathbf{1}}\right)-\Phi \mathrm{t} \cos \mathrm{wt}$

At $\mathrm{w} t=\pi$ from the instant of closing the switch equation becomes

$\Phi \mathrm{t}=(\Phi \mathrm{m}+\Phi \mathrm{r}) \boldsymbol{e}^{\wedge}(-\boldsymbol{r} \mathbf{1} \pi / \mathrm{L} 1 \omega)-\Phi \mathrm{mcos} \pi$

Usually $\omega \mathrm{L} 1>>\pi \mathrm{r} 1$, consequently $\boldsymbol{e}^{\wedge}(-\boldsymbol{r} \mathbf{1} \pi / \mathrm{L} 1 \omega)$

$[\omega \mathrm{t}=\pi]$

In subsequent half periods $\Phi t$ gradually decease till it reduce and the core flux requires the steady-state value. Because of the low time constant of the transformer circuit, distortion effects will be generated of the transient may last several seconds. The transformer switching transient pluses is referred to as the inrush current. The initial core flux is not be zero as assumed above but some residual flux value $\Phi$ r. Because of retentivity, as shown in fig the transient will now be even more severe, resultan $\Phi \mathrm{t}=\Phi \mathrm{m}+\Phi \mathrm{r}$ and the core flux will now go through the high value of $(2 \Phi m+\Phi r)$ as shown in fig 5 .

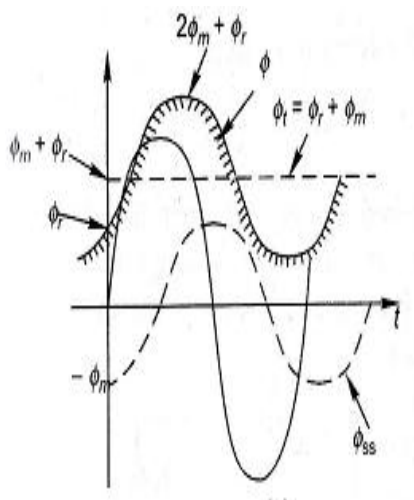

(e)

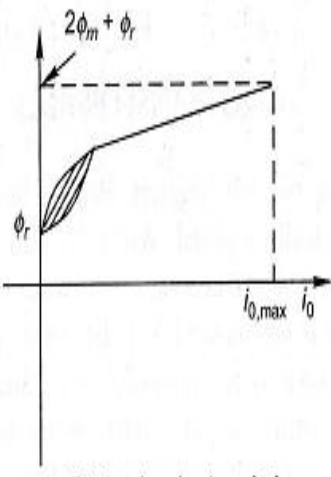

(f) Very low hysteresis loss
Figure 3: Magnetic inrush current

\section{Circuit Description}

An IC TCA785 as a zero crossing detector was used to control the phase shift of the thyristor at the angle between 0 degree to 90 degree. The angle of thyristor is reduce then magnetic inrush current is reduce. Tha angle of thyristor is depend on magnetic inrush current. The phase angle control , microcontroller, optocoupler, phase detector electronics devices are used to control the magnetic inrush current. The switched dinister diode thyristor devices are capable for switching current pluse. The principal of switched dinister diode thyristor operation are consider powerful control from blocking conducting state. During working of transformer high magnetic inrush current is rapidly amd simultaneously filled by an electronic hole plasma .

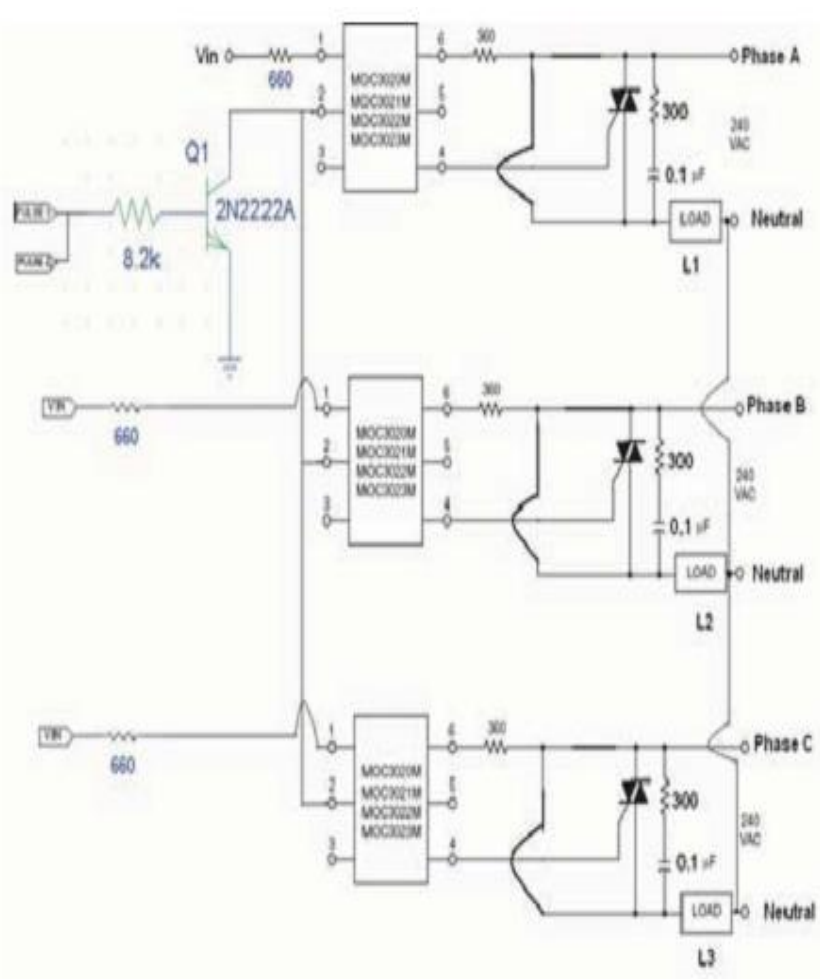

Figure 4: connection of magnetic inrush current with load

Figure 4 show the main circuit diagram, the primary of the transformer is connected to the point on wave switching circuit. In this circuit TRIAC is used to switching the cycle during the inrush current is drawn. The TRIAC first terminal is connected to supply side and second terminal is connected to the load side. The gate terminal of the TRIAC is connected to the optocoupler. The input of the optocoupler is the output of the peak detector circuit. The devices are used in each phase for controlling the magnetic inrush curren

The peak detector detect the first peak value and send the these signal to the optocoupler. The TRIAC fires to control the phase angle in between 0 to 90 degree. After closing the cycle the relay is operate to trip the circuit. The magnetic inrush current is reduce 2 to 3 times which is before the 6 to 7 times full load current. This occur due to magnetic circuit current lags by an angle . 


\section{International Journal of Science and Research (IJSR) \\ ISSN (Online): 2319-7064}

Index Copernicus Value (2013): 6.14 | Impact Factor (2014): 5.611

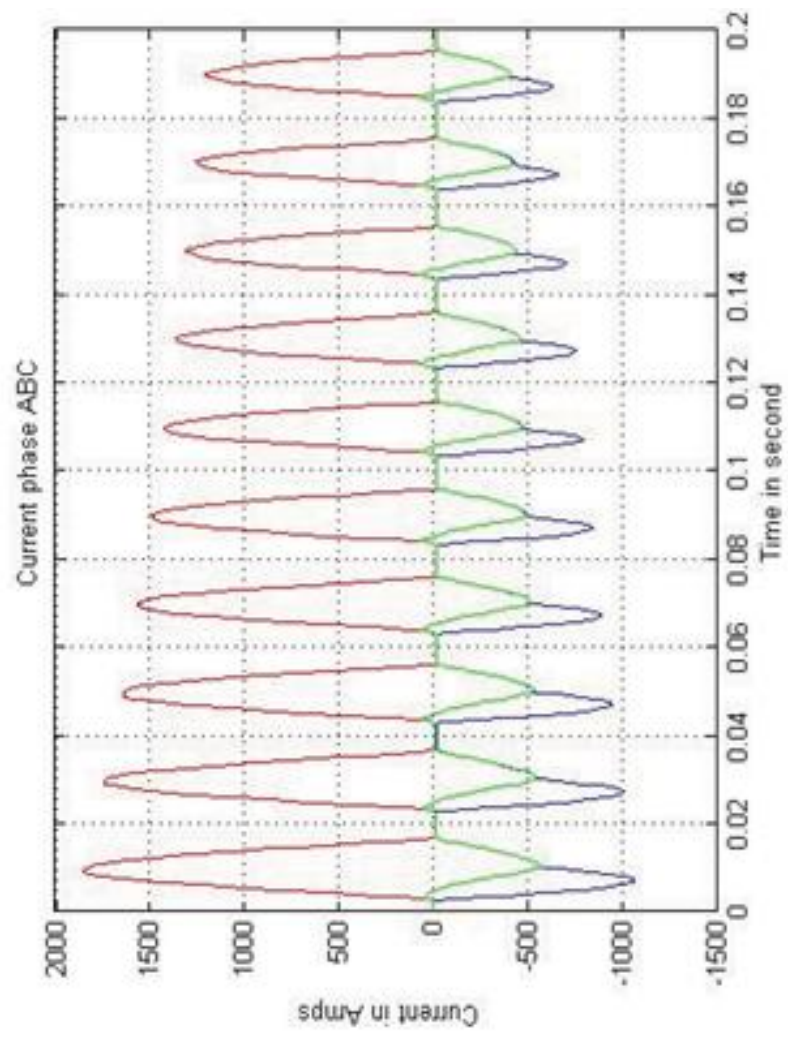

Figure 5: Without Reduction in magnetic inrush current

Magnetic inrush current when zero degree to TRIAC. The circuit breaker is provided separate to each phase controlling magnetic inrush current. For phase 1 control the angle 0 to 90 degree $5 \mathrm{msec}$ time required. The second phase control the phase angle $120+90=210$ degree $11.66 \mathrm{msec}$ time required. For third phase control the phase angle $240+90=330$ degree $18.33 \mathrm{msec}$ time required.

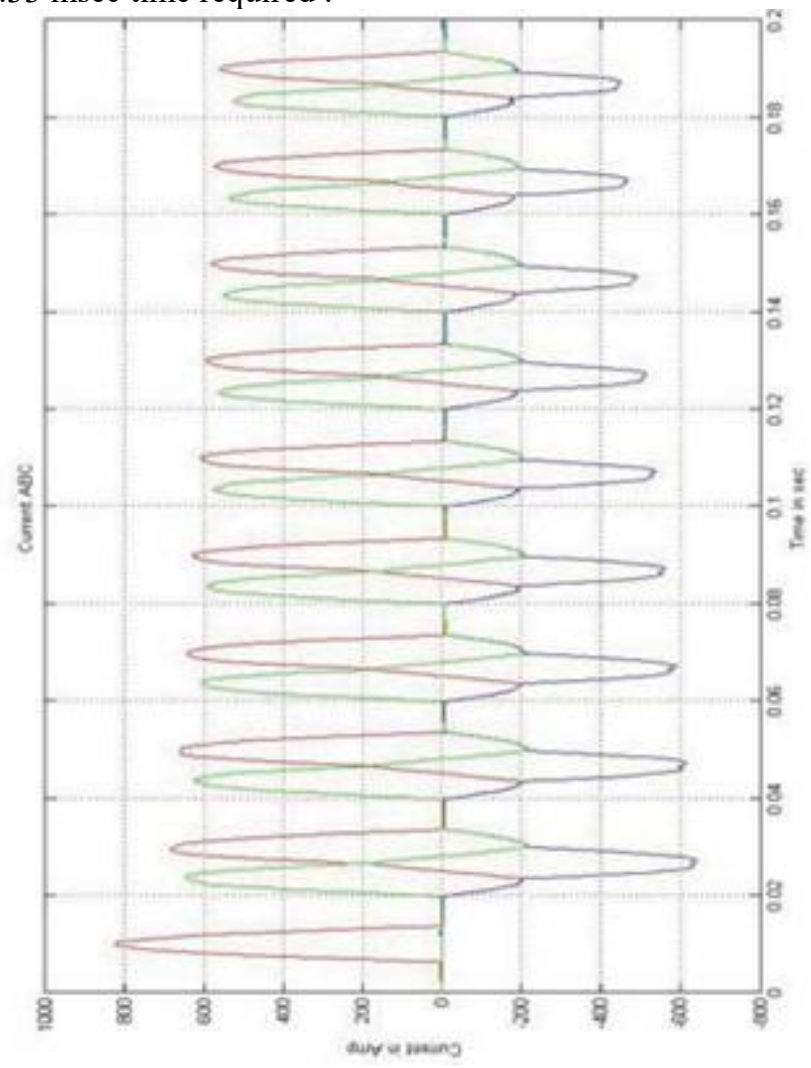

Figure 6: Reduce the magnetic inrush current

\section{Conclusions}

This paper discuss on the reduce the magnetic inrush current by point on wave switching method. The magnetic inrush current is reduce using the delay angle of thyristor. The system performance is improve, saturation on the system is also reduce.

\section{References}

[1] "Reduction of three-phase transformer magnetizing inrush current by use of point on wave switching" F. Fard Ali Asghar, and K. P. Basu. 978-1-4244-5187-6/09/ (C2009 IEEE pp $368-369$

[2] "Study of the Inrush Current Identification Using the Improved Half-Cycle Fourier Analysis" Duan Jiandong Wu Chang Yu Jianming .978-1-4244-2487-0/09/C2009 IEEE

[3] "Inrush Current Control of a DC/DC Converter Using MOSFET" Gaddam Mallesham, and Keerthi Anand. 07803-9772-X/06/ C2006 IEEE

[4] Yu Cui, G. Sami, -A sequential phase Energization technique for transformer inrush current reduction- part 1st: simulation \& experimental results\|, IEEE Transactions on power delivery, 2 April 2005

[5] J. F. Holcomb, Distribution transformer magnetizing inrush current, Transactions of the American Institute of Electrical Engineers, Part III (Power Apparatus and Systems), vol. 80, no. 57, pp. 697-702, Dec. 1961. 